\title{
Surface Micromachined Solenoid On-Si and On-Glass Inductors for RF Applications
}

\author{
Jun-Bo Yoon, Student Member, IEEE, Bon-Kee Kim, Chul-Hi Han, Member, IEEE, \\ Euisik Yoon, Member, IEEE, and Choong-Ki Kim, Fellow, IEEE
}

\begin{abstract}
RF performance of surface micromachined solenoid on-chip inductors fabricated on a standard silicon substrate (10 $\Omega \cdot \mathbf{c m})$ has been investigated and the results are compared with the same inductors on glass. The solenoid inductor on $\mathrm{Si}$ with a 15- $\mu \mathrm{m}$ thick insulating layer achieves peak quality $(Q-)$ factor of 16.7 at $2.4 \mathrm{GHz}$ with inductance of $2.67 \mathrm{nH}$. This peak $Q$-factor is about two-thirds of that of the same inductor fabricated on glass. The highest performance has been obtained from the narrowestpitched on-glass inductor, which shows inductance of $2.3 \mathrm{nH}$, peak $Q$-factor of 25.1 at $8.4 \mathrm{GHz}$, and spatial inductance density of $30 \mathrm{nH} / \mathrm{mm}^{2}$. Both on-Si and on-glass inductors have been modeled by lumped circuits, and the geometrical dependence of the inductance and $Q$-factor have been investigated as well.
\end{abstract}

Index Terms - High $Q$, integrated inductor, micromachining, on-chip solenoid inductor, RF MEMS.

\section{INTRODUCTION}

A $\mathrm{N}$ on-chip inductor is the last passive monolithic component that still needs active research for the improvement of its performance such as accurate inductance with small device area, high-quality $(Q-)$ factor, and high peak- $Q$ frequency. Although discrete inductors are fabricated as a solenoid type, on-chip inductors are usually fabricated as planar types such as meander or commonly spiral type since the three-dimensional (3-D) structure of the solenoid is difficult to realize by the conventional integrated circuits (IC) technology. For highperformance on-Si spiral inductors, reduction of substrate loss and metal resistance have been the key areas for improvement. For reducing the substrate loss, various methods have been reported such as use of a high resistivity substrate [1], etching the substrate underneath inductors [2], or insulating the inductors from the substrate using a thick polyimide [3], an oxidized porous silicon (OPS) layer [4], and high-dose proton beams [5]. For reducing the metal resistance, thick gold metallization [1], multiple metal layers in parallel [6], or copper metallization [7] have been reported.

Recently, solenoid on-chip inductors have been proposed as an alternative solution for high-performance inductors using 3-D laser lithography [8] or several micromachining technologies [9]-[11] to minimize both parasitic capacitive coupling to the substrate and inductor area. In our previous works, we proposed a novel method for fabricating monolithic solenoid inductors using simple surface micromachining [10] and inves-

Manuscript received January 21, 1999; revised May 11, 1999.

The authors are with the Department of Electrical Engineering, Korea Advanced Institute of Science and Technology, Taejon 305-701, Korea.

Publisher Item Identifier S 0741-3106(99)07051-2.

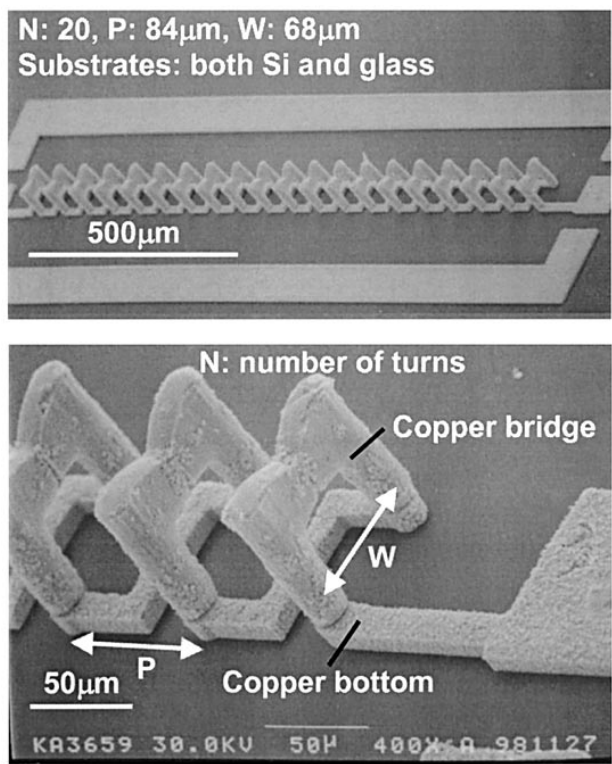

Fig. 1. SEM photographs of the fabricated 20-turn, all-copper solenoid inductor (upper: overview, lower: magnified view).

tigated the RF performance of the solenoid inductors fabricated only on glass [11].

In this letter, we newly report experimental results for the "on-Si" inductors, which are of more practical importance, as well as on-glass inductors. Also, performance of on-glass inductors has been improved by a slight modification of the structural design, and geometrical dependence of the inductance and $Q$-factor are substantially presented as well.

\section{DESIGN AND FABRICATION}

We have changed the solenoid design from the previous inclined top and bottom conductor type [11] to the parallel type (Fig. 1) to reduce the parasitic capacitance between the top and bottom conductor lines. The bottom conductor has $10 \mu \mathrm{m}$ thickness, $14 \mu \mathrm{m}$ width, and the top conductor has $30 \mu \mathrm{m}$ thickness and $18 \mu \mathrm{m}$ width, respectively. The center-to-center height of the solenoid inductor is $70 \mu \mathrm{m}$. We have fabricated solenoid inductors on both $\mathrm{Si}$ and glass wafers for separating the inductor-only performance and the substrate effect. The solenoid inductors have been monolithically fabricated using only simply-modified conventional lithography and wellestablished copper electroplating at a low process temperature below $120^{\circ} \mathrm{C}$. The fabrication steps in detail were reported previously [10], [11]. 


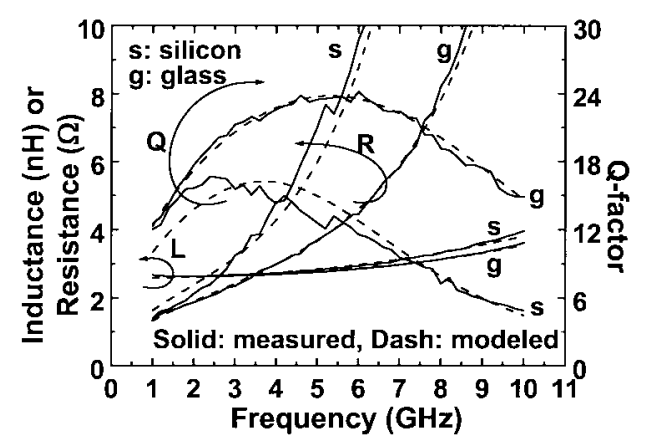

(a)

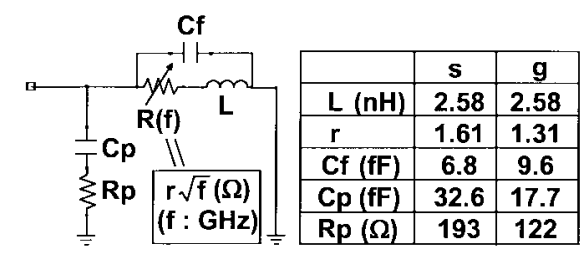

(b)

Fig. 2. Comparison of inductor performances of the two identical on-Si and on-glass solenoid inductors shown in Fig. 1. (a) Measured and modeled $\mathrm{RF}$ characteristics and (b) equivalent lumped-circuit model and parameters. The equivalent circuit parameters are extracted by EEsof Libra simulator. Substrates: s (silicon) $540-\mu \mathrm{m}$ thick p-type $\mathrm{Si}(10-23 \Omega \cdot \mathrm{cm}) / 1-\mu \mathrm{m}$ thick thermal oxide/14- $\mu \mathrm{m}$ thick hard-cured photoresist, and g (glass) $560-\mu \mathrm{m}$ thick Corning \#7740 glass.

\section{RESUlts AND Discussion}

Fig. 1 shows a 20-turn, all-copper solenoid inductor fabricated on both $\mathrm{Si}$ and glass substrates. The one-port $S$-parameters of the fabricated inductors were obtained from their two-port $S$-parameters which were measured in RF band $(1-10 \mathrm{GHz})$ by Wiltron $360 \mathrm{~B}$ vector network analyzer and Cascade on-wafer probes. Fig. 2 compares the performances of two identical on-Si and on-glass inductors shown in Fig. 1. The measured and modeled RF characteristics, the equivalent lumped-circuit model and parameters are also shown in Fig. 2. For the on-Si inductor, the pad-parasitics on the Si wafer were de-embedded using the dummy pattern, which has only pad patterns. The de-embedded on-Si inductor exhibits inductance of $2.67 \mathrm{nH}$ and peak $Q$-factor of 16.7 at peak- $Q$ frequency of $2.4 \mathrm{GHz}$. The on-glass inductor shows same inductance and larger peak $Q$-factor of 24.2 at $6 \mathrm{GHz}$, which also indicate substantial improvement over the results reported earlier (2.5 nH, peak $Q$-factor of 19 at $5.5 \mathrm{GHz}$, [11]). Based on the Greenhouse's equation [12] applied to the microscale solenoid structure [13], the calculated inductance value was $2.53 \mathrm{nH}(6 \%$ error). Other measured inductance values $(2.67-11.2 \mathrm{nH})$ were within $10 \%$ of the calculated values. By comparing the equivalent circuit parameters in Fig. 2, it can be easily understood that the inferior $Q$-factor performance of the on-Si inductor originates from the relatively large increase in the parasitic capacitance to the substrate.

Fig. 3 shows the geometrical dependence of the inductance and peak $Q$-factor of the on-glass inductors. Unlike spiral inductors, Fig. 3(a) exhibits a good linear relationship between inductance and the number of turns $(0.137 \mathrm{nH} / \mathrm{turn})$. Meanwhile, the on-silicon inductors have shown $0.136 \mathrm{nH} / \mathrm{turn}$.

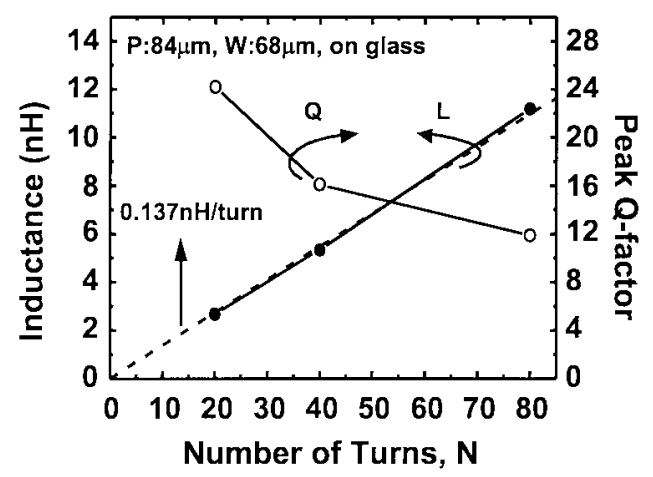

(a)

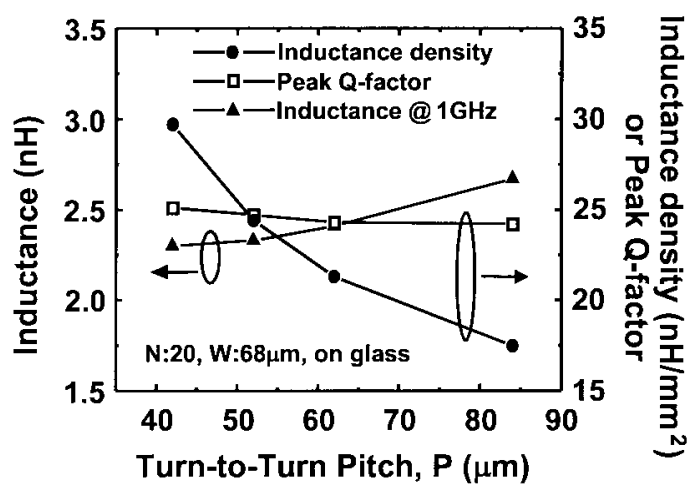

(b)

Fig. 3. Geometrical dependence of the inductance and peak $Q$-factor of the solenoid on-glass inductors (a) number-of-turns (N) variation and (b) turn-to-turn pitch $(\mathrm{P})$ variation. All the inductance values are obtained at $1 \mathrm{GHz}$ and the height of all solenoid inductors is $70 \mu \mathrm{m}$.

It should be noted that this linear relationship is very important and advantageous in designing accurate inductance and this cannot be obtained from spiral inductors. Fig. 3(b) shows the effect of the turn-to-turn pitch on the inductor performance. We have obtained spatial inductance density as high as $30 \mathrm{nH} / \mathrm{mm}^{2}$ from the on-glass inductor with narrowest pitch of $42 \mu \mathrm{m}$, and the inductor also shows highest peak $Q$ factor of 25.1 at $8.4 \mathrm{GHz}$ with inductance of $2.3 \mathrm{nH}$. The on-silicon inductors have shown the same pitch-to-inductance relationship within $2 \%$ difference in inductance values from those of the on-glass inductors. It should be noted that a narrower pitch is favorable for smaller device area, higher peak $Q$-factor and higher peak- $Q$ frequency in spite of a little decrease in inductance. Also, we have observed that inductance relates to the inductor width simply by a firstorder. Solenoid inductors with more than $68 \mu \mathrm{m}$ in width were fabricated using dummy posts [11].

\section{COnClusions}

RF performance of surface micromachined solenoid on-chip inductors fabricated on both $\mathrm{Si}$ and glass substrates has been investigated. The fabricated on-Si and on-glass inductors show high peak $Q$-factors of up to 16.7 and 25.1 at $\mathrm{GHz}$ ranges, respectively and they are well modeled by lumped circuits. The solenoid on-chip inductors fabricated here have many desirable aspects, such as high performance even on a Si substrate, 
linear relationships between inductance and the number of turns, scaling merits by reducing the turn-to-turn pitch, and high-current capability by thick metallization. These solenoid on-chip inductors can be used for various RF applications such as RF power amplifiers requiring high-current inductor loads, various RF filters and voltage-controlled oscillators (VCO's).

\section{ACKNOWLEDGMENT}

The authors thank S.-H. Jeon, Y.-H. Cho, Y.-J. Kim, and K.-M. Koh for technical assistance in RF measurement, C.-S. Lee for SEM photos, and all members in MiDAS and IML Laboratories at KAIST for their valuable supports on this work.

\section{REFERENCES}

[1] K. B. Ashby, I. A. Koullias, W. C. Finley, J. J. Bastek, and S. Moinian, "High $Q$ inductors for wireless applications in a complementary silicon bipolar process," IEEE J. Solid-State Circuits, vol. 31, pp. 4-9, Jan. 1996.

[2] J. Y.-C. Chang, A. A. Abidi, and M. Gaitan, "Large suspended inductors on silicon and their use in a $2-\mu \mathrm{m}$ CMOS RF amplifier," IEEE Electron Device Lett., vol. 14, pp. 246-248, May 1993.

[3] B.-K. Kim, B.-K. Ko, and K. Lee, "Monolithic planar RF inductor and waveguide structures on silicon with performance comparable to those in GaAs MMIC," in IEDM Tech. Dig., 1995, pp. 717-720.

[4] C.-M. Nam and Y.-S. Kwon, "High-performance planar inductor on thick oxidized porous silicon (OPS) substrate," IEEE Microwave Guided Wave Lett., vol. 7, pp. 236-238, Aug. 1997.
[5] C. Liao, T.-H. Huang, C.-Y. Lee, D. Tang, S.-M. Lan, T.-N. Yang, and L.-F. Lin, "Method of creating local semi-insulating regions on silicon wafers for device isolation and realization of high- $Q$ inductors," IEEE Electron Device Lett, vol. 19, pp. 461-462, Dec. 1998.

[6] J. N. Burghartz, M. Soyuer, K. A. Jenkins, and M. D. Hulvey, "High- $Q$ inductors in standard silicon interconnect technology and its application to an integrated RF power amplifier," in IEDM Tech. Dig., 1995, pp. $1015-1017$

[7] J. N. Burghartz, D. C. Edelstein, K. A. Jenkins, C. Jahnes, C. Uzoh, E. J. O'Sullivan, K. K. Chan, M. Soyuer, P. Roper, and S. Cordes, "Monolithic spiral inductors fabricated using a VLSI Cu-damascene interconnect technology and low-loss substrates," in IEDM Tech. Dig., 1996, pp. 99-102.

[8] D. J. Young, V. Malba, J.-J. Ou, A. F. Bernhardt, and B. E. Boser, "Monolithic high-performance three-dimensional coil inductors for wireless communication applications," in IEDM Tech. Dig., 1997, pp. 67-70.

[9] Y.-J. Kim and M. G. Allen, "Surface micromachined solenoid inductors for high frequency applications," IEEE Trans. Comp. Packag. and Manufact. Technol. C, vol. 21, pp. 26-33, Jan. 1998.

[10] J.-B. Yoon, C.-H. Han, E. Yoon, and C.-K. Kim, "Monolithic fabrication of electroplated solenoid inductors using three-dimensional photolithography of a thick photoresist," in press, Jpn. J. Appl. Phys., vol. 37, pt. 1, no. 12B, Dec. 1998.

[11] J.-B. Yoon, B.-K. Kim, C.-H. Han, E. Yoon, K. Lee, and C.-K. Kim, "High-performance electroplated solenoid-type integrated inductor (SI2) for RF applications using simple 3-D surface micromachining technology," in IEDM Tech. Dig., 1998, pp. 544-547.

[12] H. M. Greenhouse, "Design of planar rectangular microelectronic inductors," IEEE Trans. Parts, Hybrids, Packaging, vol. PHP-10, pp. 101-109, June 1974.

[13] Y.-S. Choi, "Fabrication and modeling of three-dimensional monolithic micro solenoid inductors," M.S. thesis, Korea Advanced Inst. Sci. Technol. (KAIST), Taejon, Korea, 1999. 